\title{
A LACUNA ENTRE O MESTRE E O PROFESSOR: DADOS ACERCA DA PRESENÇA DE DISCIPLINA VOLTADA A ENSINO NOS CURRÍCULOS DE CURSOS DE MESTRADO EM DIREITO NO BRASIL
}

\author{
THE GAP BETWEEN THE TEACHER AND THE MASTER: DATA ON THE \\ PRESENCE OF A DISCIPLINE CENTERED ON TEACHING IN CURRICULA OF \\ MASTER OF LAWS PROGRAMS IN BRAZIL
}

\author{
${ }^{1}$ Lahis Pasquali Kurtz \\ ${ }^{2}$ Anna Clara Lehmann Martins
}

\section{RESUMO}

Os cursos de direito no Brasil carecem de professores cuja abordagem de ensinoaprendizagem vá além da tradicional. Este artigo busca observar se a formação oferecida aos professores de direito no nível mínimo exigido deles por lei - mestrado - caminha em direção a suprir essa necessidade. Analisaram-se currículos de mestrado em direito a fim de verificar se ofertam aos mestres capacitação para ensino, comparando-a com a importância dispensada no currículo à pesquisa e à produção da dissertação. Apresentam-se conclusões obtidas desses dados e possíveis aprofundamentos nesse campo de investigação a fim de pensar mudanças para a realidade do ensino jurídico.

Palavras-chave: Ensino jurídico, Currículos de mestrado, Magistério superior

\begin{abstract}
Law schools in Brazil lack professors whose teaching approach goes beyond traditional. This article seeks to observe if the training offered to law professors at the basic level required by law - master's degree - goes someway towards fulfilling this need. Curricula of master of law programs are analyzed to verify if they offer masters teaching training, comparing these results with the importance given to research and the dissertation in the curricula. This work presents conclusions obtained from these data and possible developments in the research field towards measures that could be adopted to enable changes in legal education's reality.
\end{abstract}

Keywords: Legal education, Master's curriculum, University teaching

\footnotetext{
${ }^{1}$ Mestranda em Direito na Universidade Federal de Santa Catarina - UFSC, Florianópolis - SC (Brasil). E-mail: lahiskurtz@gmail.com

${ }^{2}$ Mestre em Direito pela Universidade Federal de Santa Catarina - UFSC, Florianópolis - SC (Brasil).

E-mail: laclaramartins@gmail.com
} 


\section{INTRODUÇÃO}

Leituras e estudos indicam uma limitação no método tradicional de ensino baseado na transmissão de conteúdos do professor ao aluno para reproduzir saberes (MIZUKAMI,

1986). Esse método é criticado por ser embasado na figura do professor como autoridade, estabelecendo uma hierarquia nos locais de aprendizagem e uma passividade do sujeito que aprende. Essa tradição mostra-se contrária à criação de um ambiente propício para a inovação e para a criatividade, que necessitam de sujeitos com relativa autonomia, questionadores e que construam o próprio conhecimento ${ }^{1}$.

Nesse sentido, há autores que retratam o que se convencionou chamar de abordagens

de ensino-aprendizagem, propondo formas de tratar a docência que se colocam como alternativas mais eficazes que a tradicional. Essas costumam ser classificadas conforme oferecem maior ou menor espaço para participação do aluno no processo de conhecimento.

Porém, as abordagens de ensino-aprendizagem alternativas à tradicional exigem prévio estudo pelo professor, sob risco de não se estar seguindo qualquer método e acabar por utilizar abordagens inadequadas e que falham em ensinar de modo efetivo. Não basta simplesmente evitar a aula expositiva para adotar outro método de ensino, é preciso compreender a concepção de aluno, professor e conhecimento envolvida em cada método. Vatan dos Santos (2005, p. 30), nesse sentido, organizou de forma bastante didática as características das diferentes abordagens, ressaltando-se aqui os aspectos relativos ao papel do professor:

Figura 1 - Resumo das diferentes abordagens do processo de ensino e aprendizagem

\begin{tabular}{|c|c|c|c|c|c|}
\hline Abordagens & Abordagem tradicional & $\begin{array}{c}\text { Abordigem } \\
\text { comportamentalista }\end{array}$ & Abordagem humanista & Abordagem cognitivista & Abordagem sociocultural \\
\hline O professor & $\begin{array}{l}\text { E o transmissor dos } \\
\text { conteúdos aos alunos. } \\
\text { Predomina como autoridade. }\end{array}$ & $\begin{array}{l}\text { E o educador que seleciona, } \\
\text { organiza e aplica um } \\
\text { conjunto de meios que } \\
\text { garantem a eficiência e } \\
\text { eficácia do ensino. }\end{array}$ & $\begin{array}{l}\text { Eo facilitador da } \\
\text { aprendizagem. }\end{array}$ & $\begin{array}{l}\text { Cria situaçốes desafiadoras e } \\
\text { desequilibradoras, pela } \\
\text { orientação. Estabelece } \\
\text { condiçôes de reciprocidade e } \\
\text { cooperação ao mesmo tempo } \\
\text { moral e racional. }\end{array}$ & $\begin{array}{l}\text { E o educador que direciona e } \\
\text { conduz o processo de ensino } \\
\text { e aprendizagem. A relaçäo } \\
\text { entre professor e aluno deve } \\
\text { ser horizontal, ambos se } \\
\text { posicionando como sujeitos } \\
\text { do ato de conhecimento. }\end{array}$ \\
\hline
\end{tabular}

Fonte: Vatan dos Santos (2005, p. 30).

\footnotetext{
1 Cabe referir a colocação de Freire (2002, p. 12) acerca da construção do conhecimento, em que afirma ser “preciso [...] que o formando, desde o princípio de sua experiência formadora, assumindo-se como sujeito também da produção do saber, se convença definitivamente de que ensinar não é transferir conhecimento, mas criar as possibilidades para a sua produção ou a sua construção".
} 
Percebe-se, na categorização proposta, que na abordagem tradicional há maior enfoque sobre a figura do professor, sendo esse destaque reduzido à medida que, nos métodos alternativos a esse, a relação entre o professor e o aluno ganha importância. Apesar disso, em qualquer das abordagens quem detém a escolha sobre o enfoque da aprendizagem será o professor. Será a partir de sua forma de enxergar a relação de ensinoaprendizagem que se poderá adotar uma ou outra perspectiva.

Nesse diapasão, a formação do professor interferirá no universo de escolhas que esse terá à sua disposição na hora de adotar uma dada abordagem. A conclusão de Vatan dos Santos (2005, p. 31) é que "o professor incorpora de certa forma um ou mais aspectos dos referenciais teóricos analisados anteriormente em suas práticas docentes, muitas das quais são derivadas de como foi educado durante sua vida escolar".

Tendo em vista essa realidade, compreende-se que é preciso uma formação especial para a docência, caso se deseje que os professores vão além do método tradicional, baseado na reprodução de conhecimentos, que é considerado limitado (embora, note-se, não desprezível). No nível de ensino fundamental e médio, isso se concretiza em certa medida, tendo-se em consideração que os professores que ali lecionam têm formação na área de pedagogia ou nas licenciaturas, e tratam o ensino e a aprendizagem como processos dotados de metodologias específicas.

Já no ensino de nível superior, a realidade da docência parece ser diversa. A percepção geral, em especial nos cursos de bacharelado, é que nem sempre os professores têm uma formação voltada ao ensino. Ademais de haver professores que possuem outra profissão concomitante (por exemplo, professores de medicina que são médicos, professores de engenharia que são engenheiros, professores de direito que são advogados, juízes etc.), percebe- se que sua formação tem enfoque maior no aprofundamento de conteúdos que fazem parte da área de conhecimento do que nas metodologias para ensinar os conhecimentos básicos da área.

Há que se considerar, nesse ponto, a legislação brasileira acerca dos cursos de pósgraduação no Brasil: o dispositivo legal aparenta estar preocupado com o aspecto da formação dos docentes de nível superior, uma vez que determina que os professores de graduação devem ter, no mínimo, pós-graduação lato sensu para poder dar aulas (sendo possível, em caráter emergencial, contratar pessoa com formação inferior, desde que ela se comprometa a cursar esse nível em um período determinado de tempo) ${ }^{2}$.

2 Essa é uma das observações da análise da legislação feita por Rodrigues (2009, p. 39). 
Nesse sentido é a conclusão da investigação de Rodrigues (2009, p. 35) acerca da regulamentação do magistério superior: "O Direito Educacional exige que todos os docentes do ensino superior brasileiro possuam pós-graduação e que essa deve incluir necessariamente conteúdos voltados à formação pedagógica”.

Assim, há uma associação legal dos títulos de especialista e mestre com a carreira docente em nível superior. Espera-se, de quem conclui tais níveis de formação, que tenha capacitação para o ensino.

Volta-se, nesse contexto, o olhar para os cursos de direito. A análise é interessante pois manifesta-se nesse mundo o problema apresentado e também o cumprimento aparente da legislação indicada: há tanto a aplicação de abordagem tradicional em sala de aula quanto o fato de os professores em geral terem pós-graduação ${ }^{3}$. Aparentemente, há uma contradição: a formação exigida para ser professor parece não formar, efetivamente, professores cuja abordagem vá além da reprodução de saberes, ou sequer profissionais com enfoque sobre a carreira docente.

Os cursos de direito no Brasil, do ponto de vista da abordagem de ensinoaprendizagem, apontam para necessidade de mudança. Nesse diapasão, há o texto de San Tiago Dantas (2010), criticando a abordagem tradicional do direito no ensino superior. Escrito originalmente em 1955, a problemática narrada ali permanece espantosamente atual, apontando para uma tendência institucional que faz "dos conhecimentos, que transmitem, um corpo estanque" (DANTAS, 2010, p. 14), e do curso jurídico um "curso de institutos jurídicos, apresentado sob a forma expositiva de tratado teórico-prático” (DANTAS, 2010, p. 16).

Verifica-se que o discurso, na área acadêmica, é de que se necessita de um novo perfil de professor da graduação em direito. Essa inovação, pela lógica de que o nível de formação exigido para ser professor é o mestrado, deveria ocorrer dentro da formação de mestres.

\footnotetext{
3 Conforme pesquisa apresentada por Ghirardi (2013), dados de 2013 do Instituto Nacional de Estudos e Pesquisas (INEP) apontavam que 70\% dos professores de direito brasileiros possuíam mestrado $(45 \%)$ ou doutorado (25\%), sendo que $28 \%$ possuíam especialização, enquanto que $2 \%$ possuíam somente graduação - havendo 8 docentes de direito que nem mesmo eram graduados. Ainda que haja discrepâncias, vê-se que a maioria dos professores de direito possui mestrado (pressupondo-se que os doutores passaram por esse nível de formação).
} 
É desse contexto que vem o questionamento originário da pesquisa aqui apresentada: os cursos de mestrado acadêmico em direito estão voltados à formação de professores? ${ }^{4}$

$\mathrm{O}$ método utilizado para tentar responder à pergunta da pesquisa é descrito na seção seguinte, sendo sucedido pelos resultados encontrados, discussão desses e, por fim, considerações finais, em que será apresentado um esboço de resposta e possibilidade de aprofundamento das investigações sobre a questão.

\section{METODOLOGIA}

Buscando investigar se a formação oferecida pelos mestrados acadêmicos em direito no Brasil possui enfoque sobre a docência, ou de alguma forma proporciona ao mestrando essa capacitação, foi feita coleta de dados. A fonte de coleta foi o site da Plataforma Sucupira (BRASIL, 2015A), que reúne dados dos programas de pós-graduação brasileiros.

Os dados coletados foram extraídos das informações acerca de disciplinas presentes nos currículos dos 89 mestrados acadêmicos de programas de pós-graduação em direito apontados como "em funcionamento" no site entre 7 e 8 de dezembro de 2015, período da busca. Foram excluídos dos resultados de pesquisa os mestrados profissionalizantes pois não estavam disponíveis seus currículos.

O objetivo foi verificar quais currículos continham disciplinas voltadas a ensino e pesquisa, e de que forma essas eram tratadas, se com viés mais teórico, prático, se havia uma disciplina exclusiva para o ensino. E, embora o resultado da busca devesse ser óbvio, uma vez que o grau de mestre é exigência para docência em nível superior, a investigação é importante pois a inserção dessas disciplinas não é expressamente obrigatória por lei, como destacou Rodrigues (2009, p. 41):

\footnotetext{
4 Sobre o tema da formação do professor de direito no âmbito de programas de pós-graduação em sentido estrito, cabe lembrar os estudos conduzidos por Pagani (2011) e Almeida (2014) - note-se, ambos pertencentes à área da educação. O presente artigo, embora trate do mesmo tema que esses trabalhos, prima por uma maior especificidade em seu recorte; em outras palavras, investiga a presença de disciplina (e não atividades em geral) voltada a ensino no currículo de cursos de mestrado (sem incluir doutorado) em direito; no currículo de cursos de mestrado (sem incluir doutorado) em direito; ademais, cuida-se de investigação que, em comparação com os estudos referidos, é mais recente.
} 


\begin{abstract}
Embora a atual legislação que trata, no Brasil, da pós-graduação (Resoluções CES/CNE $n^{\circ} 1 / 2001$ e $n^{\circ} 1 / 2007$ ) não indique expressamente, em nenhum momento, a necessidade de incluir, quer seja na pós-graduação lato sensu, quer seja na pós- graduação stricto sensu, atividades voltadas à formação didáticopedagógica, essa exigência decorre, necessariamente, do objetivo institucional desses cursos, em sua configuração acadêmica, qual seja o de formar docentes e pesquisadores.
\end{abstract}

Assim, pretendeu-se analisar a visão que os mestrados em direito adotam com relação à disciplina de metodologia do ensino, se é dada a ela relevância diversa da metodologia da pesquisa, e se há menor caráter teórico em relação ao ensino. Por disciplina de caráter teórico, compreendeu-se qualquer uma que contivesse no título as palavras "ensino", "metodologia", "método", "educação" e sinônimos que apontem para a temática docente, e ao mesmo tempo não contivesse em sua nomenclatura as palavras "prática", “estágio", "tirocínio" e sinônimos. Considerou-se como disciplina prática, por sua vez, aquela que apresentasse essa última terminologia no título. A distinção deu-se pela nomenclatura, buscando nesses termos a indicação de que, nas disciplinas práticas, o mestrando assumiria o papel de professor, enquanto nas de caráter teórico haveria a discussão sobre a docência com o mestrando no papel de aluno. Em geral, estas são disciplinas com nome "metodologia" ou sinônimos, enquanto aquelas são denominadas "estágio" ou sinônimos.

Para coletar os dados, acessou-se o link "dados cadastrais do programa" na Plataforma Sucupira, preenchendo-se o campo "área de avaliação" com o termo "direito" e no campo "situação do programa" foi marcado o termo "em funcionamento". Dessa consulta, resultou a lista de 89 mestrados acadêmicos de direito que são registrados junto à Coordenação de Aperfeiçoamento de Pessoal de Nível Superior (Capes) no país.

Após, acessou-se o link "informações do programa", o item "disciplinas", e preencheu- se o campo "instituição de ensino" com o nome da instituição, selecionando-se no campo "programa" aquele correspondente à área jurídica. Dessa consulta, foi possibilitado acesso à lista de disciplinas do currículo do Programa consultado. Nessa listagem, foram buscadas manualmente (por leitura) as disciplinas relativas a metodologia de pesquisa, dissertação, ensino e prática de docência, copiando-as para uma planilha (Apêndice 1). 
Dessa prévia análise, formulou-se um questionário estruturado na plataforma Google Drive a fim de organizar e gerar informação gráfica quantitativa sobre os dados coletados, que consistiu no seguinte:

Figura 2 - Formulário utilizado na coleta de dados

Ensino e pesquisa nos PPGDs do Brasil

\section{Instituição}

\section{Mestrado acadêmico em}

Conceito CAPES
- $\square 6$
- 55
- 4
- 3

Possui disciplina voltada a ensino no currículo?
- $\mathrm{S}$ Sim
- $\square$ Não
- $\square$ Currículo indisponível

Possui disciplina voltada a pesquisa no currículo?

- $\quad$ Sim
- $\quad$ Não
$\circ \quad \square$ Currículo indisponível

Quantas disciplinas voltadas a pesquisa ou à dissertação?

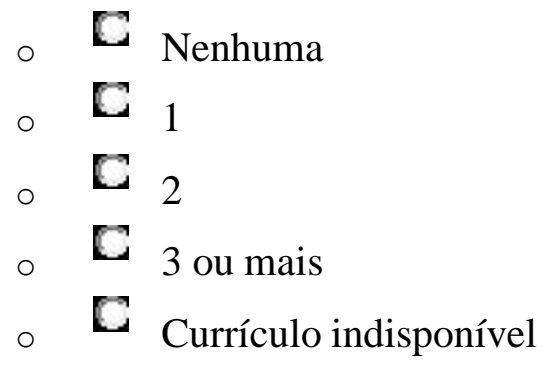

Quantas disciplinas voltadas a ensino ou prática docente?
- $\mathrm{C}$ Nenhuma
- $\mathbb{C}_{1}$
$\circ \square_{2}$ 
- $\boldsymbol{C}_{3 \text { ou mais }}$
- Currículo indisponível

A disciplina voltada a ensino é em conjunto com a voltada à pesquisa?

- $\square$ Não há disciplina

- $\mathrm{C}$ Sim

- $C_{\text {Não }}$

- $\square$ Currículo indisponível

A disciplina voltada a ensino é somente a de prática docente?

- $\square$ Não há disciplina

- $\square \operatorname{Sim}$

- L Não $^{2}$

- C Currículo indisponível

A disciplina voltada a ensino é em conjunto com a de prática docente?

- $\square$ Não há disciplina

- $\mathrm{S}$ Sim

- $C_{\text {Não }}$

- $\square$ Currículo indisponível

Qual(is) o(s) nome(s) da(s) disciplina(s) voltada(s) a ensino?

Qual(is) o(s) nome(s) da(s) disciplina(s) voltada(s) a pesquisa?

Fonte: Autoria própria (ENSINO..., 2015A).

Algumas questões foram acrescentadas devido a observações da prévia análise. O nome do curso de mestrado acadêmico foi inserido pois algumas instituições possuíam mais de um mestrado na área jurídica. O conceito Capes foi inserido pois era dado disponível na Plataforma Sucupira, de forma que se pode verificar se é possível ou não estabelecer relação direta entre a presença de disciplina voltada ao ensino e o conceito do curso de mestrado.

As questões acerca de disciplina voltada a pesquisa foram acrescentadas pois verificou-se, em muitos currículos, que pesquisa e ensino eram tratados na mesma disciplina, bem como que em alguns casos a disciplina de pesquisa assumia maior destaque que o ensino, havendo várias disciplinas sobre a temática. Dessa impressão, buscou-se 
verificar também se os currículos de mestrado realmente priorizam a pesquisa em comparação com o ensino (uma hipótese formulada com base na forma de avaliação da Capes, que deposita enfoque sobre a produção acadêmica ${ }^{5}$ ), objetivando formar mestres mais pesquisadores que professores.

O questionário foi aplicado a cada um dos currículos, resultando em quadro e gráficos com a quantidade de mestrados acadêmicos que possuem, em seus currículos, disciplina voltada ao ensino, disciplina voltada à pesquisa, se a disciplina voltada ao ensino é somente prática, se ensino e pesquisa são tratados na mesma disciplina, bem como se a parte teórica sobre ensino é aliada à prática.

As respostas às perguntas foram dadas observando-se a nomenclatura das disciplinas que foram consideradas de "ensino" ou de "pesquisa", observando-se a presença de termos como "metodologia", "educação", "estágio", "docência”, "prática", “dissertação", "pesquisa", "ensino", entre outros nessa linha, pelo que se considerou relevante coletar também os nomes das disciplinas integrantes da amostra. Os resultados encontrados são apresentados na seção a seguir.

\section{RESULTADOS}

Da aplicação do formulário aos currículos, obtiveram-se os seguintes gráficos, gerados automaticamente a partir das respostas:

É possível conferir os dados coletados para avaliação no manual disponibilizado na Plataforma Sucupira (BRASIL, 2015B). Há pouca referência a atividades de ensino propostas, porém há muitos itens relativos a produção bibliográfica e campo relativo a projetos de pesquisa. 
Figura 3 - Resultados da coleta de dados acerca dos Mestrados Acadêmicos em Direito na Plataforma Sucupira

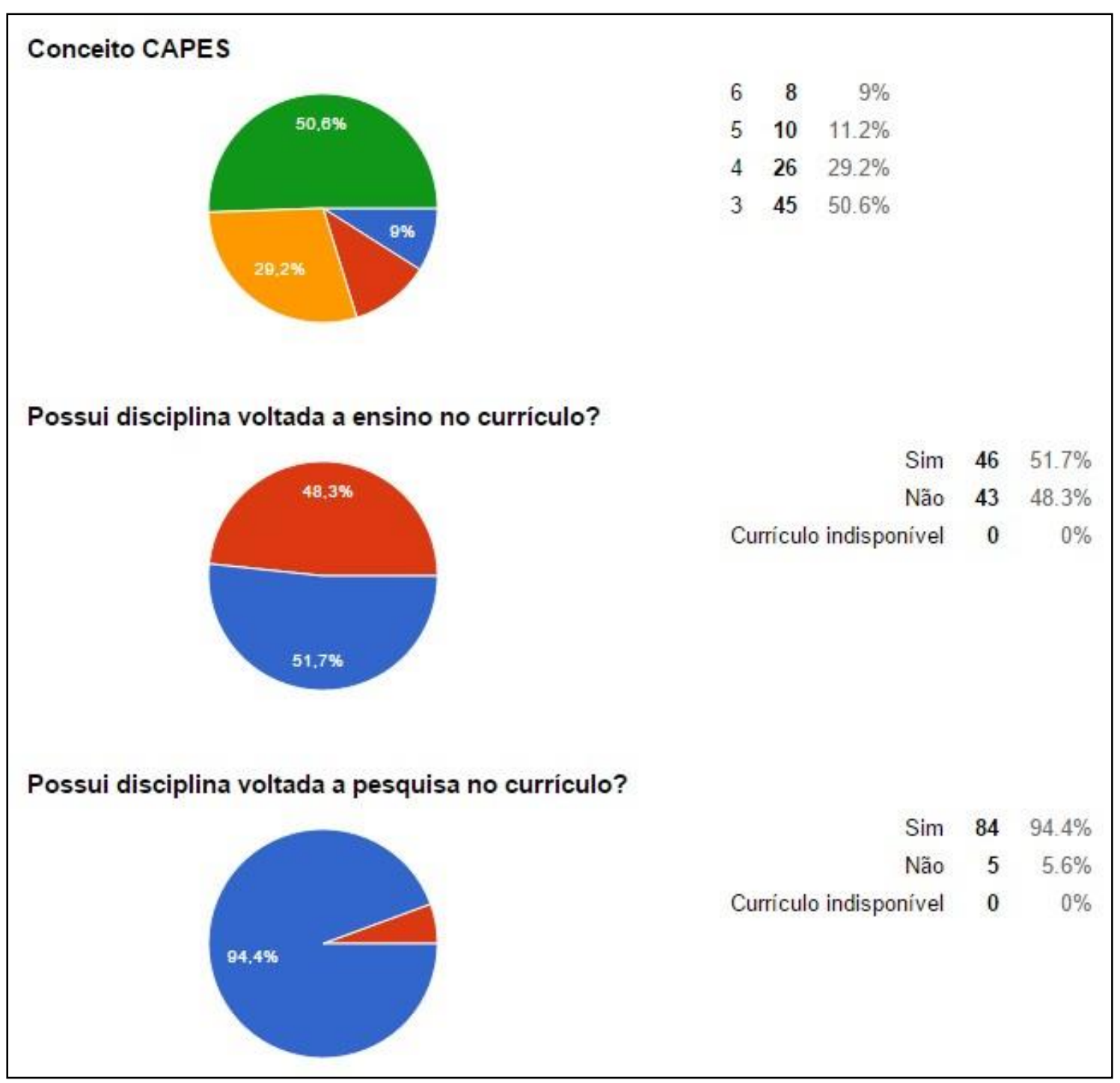




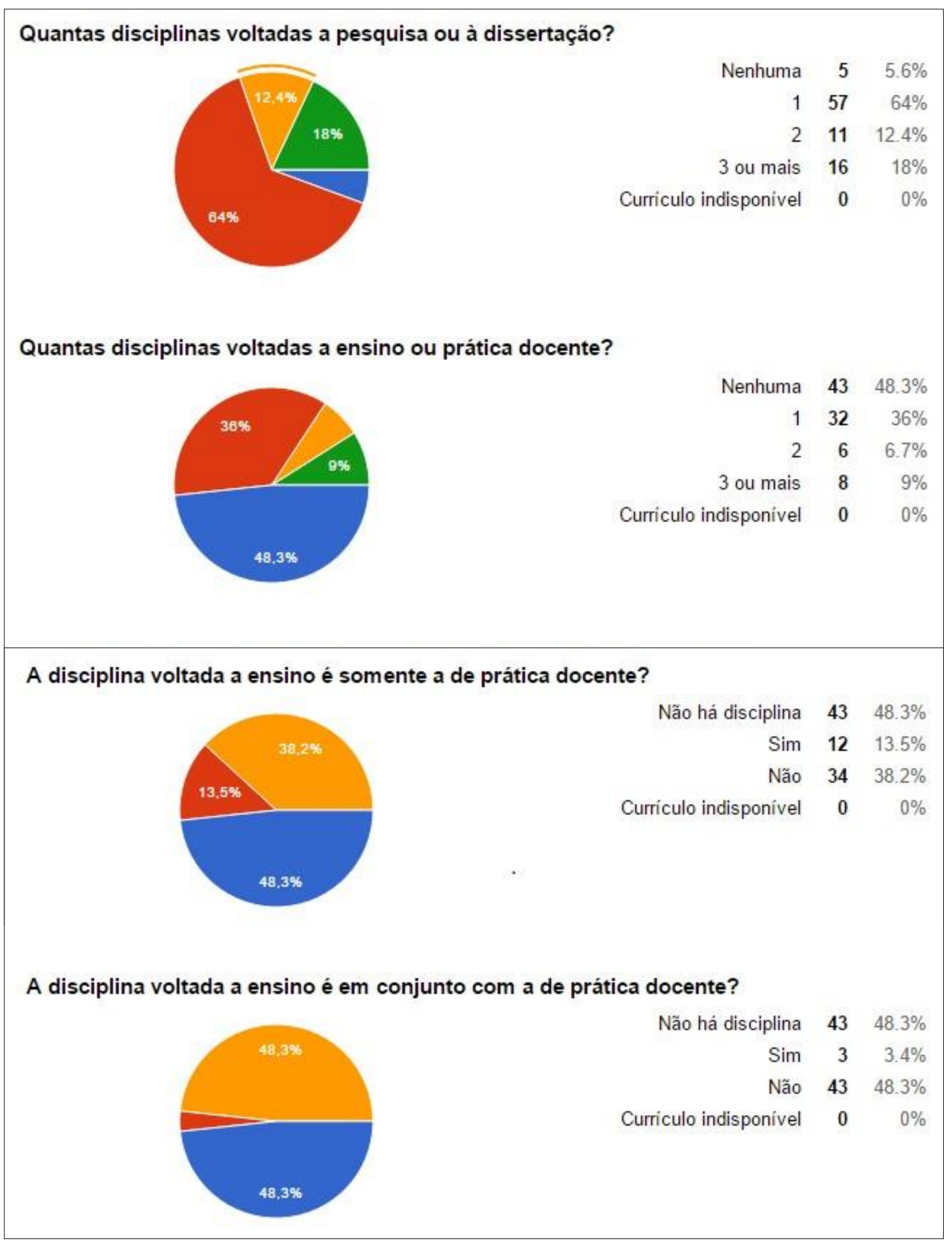

Fonte: Autoria própria (ENSINO..., 2015C)

Quanto aos nomes das disciplinas voltadas ao ensino e à pesquisa, obteve-se a listagem que pode ser conferida no apêndice do presente trabalho. Ademais dos gráficos, 
obteve-se uma planilha com as respostas associadas a cada instituição, disponível online ${ }^{6}$. Embora não tenha sido o escopo desse trabalho, é possível ali verificar quais instituições têm enfoque curricular sobre ensino e pesquisa, e de que forma as disciplinas são tratadas (ao menos superficialmente, pelo título dado).

\section{DISCUSSÃO}

Os gráficos apontam que somente 46 cursos, ou seja, pouco mais da metade, apresentam em seu currículo ao menos uma disciplina voltada ao âmbito pedagógico, indicando que o enfoque do mestrado em direito não repousa precipuamente sobre o ensino. Poder-se-ia indagar se há relação entre esse dado e o conceito qualitativo atribuído ao curso pela Capes. Pois bem: verifica-se que a minoria dos mestrados acadêmicos em direito apresentam conceitos altos, tais como 5 e 6 (18 cursos), estando a maioria (45 cursos) na nota mais baixa possível para cursos de pós-graduação em funcionamento, que é 3 . Considerando tais números, não é possível divisar relação direta entre a nota e o elemento “ensino" no currículo de disciplinas.

Mesmo quando são analisados os resultados por amostra de cada conceito, não se altera a realidade do enfoque sobre o ensino: enquanto entre os cursos com conceito Capes 3 somente

22 dos 45 possuem disciplina voltada ao ensino, e entre os cursos com conceito 4 esse número é 13 de 26, ou seja, praticamente 50\% em ambos os casos, entre os cursos com conceitos 5 e 6 , o número é 11 de 18 , ou seja, aproximadamente $61 \%$.

A diferença entre o percentual de currículos com conceitos superiores e inferiores que apresentam disciplina voltada a "ensino" é de 10 pontos percentuais, sendo que em nenhum caso chega-se a mais de $70 \%$ dos currículos com a disciplina dentro de determinada faixa de avaliação. Desse modo, em primeira análise, não se pode apontar para o enfoque sobre o ensino, enquanto disciplina, como componente de peso na atribuição de conceito feita pela Capes.

6 No endereço eletrônico: <https://drive.google.com/open?id=1XWxiu2XU4rBhk6y04GpoCwn9dKOO- HyzcipzPKjzRgU〉. 
Com efeito, consultando-se as instruções do manual de apresentação de propostas de cursos novos, conforme consta na Plataforma Sucupira (BRASIL, 2015B), bem como os itens da última avaliação trienal feita pela Capes sobre os cursos de pós-graduação em direito (BRASIL, 2015C), verifica-se que não há critérios de pontuação especificamente voltados a atividades preparatórias para docência. A ênfase antes recai sobre a quantidade de publicações e defesas, bem como a intensidade de internacionalização do curso. $\mathrm{O}$ mais próximo que se chega a um incentivo expresso ao ensino, para além das exigências de capacitação do pessoal do quadro de docentes, é a sugestão de metodologia de ensino para educação superior como tema de livro a ser publicado.

Quanto à preparação para pesquisa, percebe-se que a presença de disciplina específica é muito maior em comparação com o ensino; 94,4\% dos cursos possuem-na. Mesmo o número de disciplinas voltadas a pesquisa ou à dissertação é mais significativo, havendo 16 casos com

3 ou mais disciplinas sobre a temática - relativamente à docência, apenas 8 currículos a contemplam em 3 ou mais disciplinas. Assim, há margem para inferir que a pesquisa é considerada ponto mais relevante que o ensino, sendo raros os cursos que não contemplam em disciplina curricular esse aspecto da formação dos mestres, enquanto quase a metade não destina um tópico específico para a docência.

Ainda, embora não se possa dizer que sejam maioria, em 37 cursos de mestrado há mais de uma disciplina capacitando para pesquisa ou para escrita da dissertação, sendo que somente em 5 não há qualquer disciplina, enquanto que em 43 programas o ensino não integra tema central de disciplina alguma do currículo. Verifica-se uma quase obrigatoriedade tradicional de ofertar uma disciplina voltada à pesquisa, enquanto que preparo para o ensino parece ser um bônus que alguns currículos contêm.

A presença marcante da pesquisa no âmbito curricular pode ser explicada, ao menos em parte, pelas exigências iminentes a que deve se ater um curso de pós-graduação para manter o conceito do programa, quais sejam, o término tempestivo dos trabalhos finais de pesquisa (i. e., dissertações) e a manutenção de quota de publicações (preferencialmente de alto nível). Pelo fato de que tais cursos se organizam em torno de tais demandas, é previsível que, a fim de refinar e potencializar a produção científica, lance-se mão de disciplina específica sobre pesquisa.

Note-se que, pela referida disciplina estar contida nos currículos de quase todos os programas de pós-graduação em direito, não se identifica, por meio das informações 
coletadas, correlação entre a disciplina de pesquisa e o conceito do curso. A disciplina de ensino, como visto acima, também não estabeleceu vínculo com a nota do programa. Ambos os dados vão na direção de que o currículo, ao menos em um primeiro momento, não se posta como elemento determinante nas avaliações nacionais de programas de pósgraduação. De fato, as menções a currículo em critérios da avaliação trienal da Capes, por exemplo, são bastante abertas e elásticas, priorizando a harmonização entre disciplinas e as áreas de concentração, sem o estabelecimento de componentes materiais fixos (vale dizer, requer-se o atendimento de quesitos formais, tais quais coerência, consistência, entrosamento entre áreas, mas não é exigida a presença de uma disciplina determinada, em termos de conteúdo).

Em face dessa liberdade dos programas na composição do quadro curricular, é lícito indagar se a inserção de critérios de avaliação mais precisos e/ou específicos sobre o currículo (p. ex., exigindo a introdução de disciplina sobre ensino, requerendo o uso do ensino como tema em certo número de disciplinas etc.) nas políticas da Capes influenciaria os cursos a terem maior preocupação com os itens básicos de formação dos mestres e com o próprio ensino ministrado por seus professores a esses - e se tal preocupação produziria os efeitos desejados. Também, caberia buscar se há tais políticas em outros países e, na medida do possível, realizar estudos acerca de seus reflexos na formação docente superior.

Tornando aos dados, outro aspecto observado foi se a disciplina de ensino contempla um momento de aprendizagem teórica e estudo acerca das abordagens de ensinoaprendizagem, o que pressupõe não concentrar o foco exclusivamente sobre a prática. Nesse ponto, observou- se que dos 46 cursos que apresentavam algum enfoque sobre ensino em seus currículos, 12 possuíam apenas a disciplina prática, o que pode apontar para uma visão, nesses currículos, de ensino como atividade intuitiva ou subjetiva, que carece de prévia formação teórico- metodológica. Ainda, em 3 dos cursos verificou-se que o ensino é tratado concomitantemente com viés teórico e prático.

Não obstante isso, na maioria dos cursos com algum enfoque sobre ensino, há, de fato, preocupação teórica. À primeira vista, esse é um dado a ser encarado positivamente embora a confirmação dessa perspectiva só possa ser adquirida com uma verificação pormenorizada dos planos de ensino; a mesma ressalva é válida para disciplinas de abordagem concomitantemente teórica e prática.

Por fim, destaca-se o fato de 13 currículos apresentarem uma disciplina conjunta para tratar de metodologia do ensino e da pesquisa. Questiona-se o motivo para tal 
abordagem, pois são duas atividades de caráter diverso, de forma que a inserção precária do ensino em meio a uma disciplina de metodologia da pesquisa, para cumprir com algum padrão de currículo, pode ser prejudicial, correndo-se o risco de fornecer uma visão superficial de ambas as atividades. É abordagem que abre caminho para investigação sobre se pesquisa e ensino podem e/ou devem andar juntos - e em que medida, a partir de quais metodologias etc.

Cabe dizer que o posicionamento acerca da separação entre ensino e pesquisa advém do fato de que as carreiras de professor e de pesquisador não necessariamente exigem o mesmo tipo de formação. Enquanto a pesquisa em geral está voltada a explorar novos ramos ou aprofundar saberes de uma área, o ensino volta-se a métodos de aprendizagem de conhecimentos básicos dessa área.

Os diferentes objetivos, por outro lado, não impedem hipóteses de harmonização entre as duas frentes. Do ponto de vista do ensino, uma abordagem conjunta possibilitaria descortinar soluções de abordagem pedagógica inovadoras; do mesmo modo, e ora pelo viés da pesquisa, tal conjunção abriria margem para novas vias de problematização e questionamento de dados estabelecidos. Sobretudo, aliar ambos os saberes - pesquisa e ensino - poderia qualificar o mestre tanto para aprofundar-se em sua área quanto para compartilhar tais conhecimentos com seus pares e discentes, sendo, por isso, uma abordagem hipoteticamente desejável. Resta verificar se as disciplinas que se propõem a tanto obtêm sucesso em sua empreitada.

Discutidos esses pontos, passa-se, afinal, às considerações finais.

\section{CONSIDERAÇÕES FINAIS}

Pelos dados aqui expostos, pode-se concluir, provisoriamente, que os mestrados acadêmicos em direito, em geral, não possuem enfoque sobre a formação de professores, ao menos em seus currículos de disciplinas. $\mathrm{O}$ ensino ocupa posto secundário em âmbito curricular, ao passo que há certo destaque para a pesquisa nessa mesma sede, podendo-se concluir que o mestrado, embora vislumbrado legislativamente como etapa de formação para docência de nível superior, é tratado pelas instituições precipuamente como fase de preparo de pesquisadores.

A legislação, note-se, aponta para uma exigência voltada ao aprimoramento dos professores, determinando formação diferenciada para o exercício superior. Ocorre que, em 
realidade - e consoante o averiguado, essa formação não parece preparar para a atividade em que é requisito. Não se vê a disciplina de metodologia do ensino como indispensável curricular, denotando a perspectiva de que o ensino é algo intuitivo, acessório - a desembocar necessariamente na abordagem tradicional.

Frente a isso, surge a necessidade de mapear com maior precisão a formação docente (ou a falta dela) nos cursos de mestrado em direito. É de se levar a cabo investigação mais aprofundada acerca dos cursos em que disciplina sobre metodologia do ensino existe, se é obrigatória ou optativa, como é seu plano de ensino, se são apresentadas as diferentes abordagens de ensino-aprendizagem, como isso é feito etc., a fim de compor um retrato mais detalhado da realidade. Também poderia ser investigada a inserção curricular e o andamento de atividades como monitorias, seminários, grupos de pesquisa ministrados por discentes de mestrado, itens cujo impacto sobre a formação docente deve ser levado em conta. Outro desdobramento poderia ser o estudo acerca da prática docente, os locais onde é obrigatória e de que forma se dá a preparação para a atividade, bem como de que forma é acompanhada.

Sublinhe-se que essas futuras pesquisas são imprescindíveis antes de qualquer proposta de alteração de critérios de avaliação de programas de pós-graduação, a fim de que, constatada a necessidade, parâmetros norteadores de mudança curricular possam ser estabelecidos com segurança.

Para além de tudo que foi dito, cabe ainda verificar se o enfoque disciplinar é realmente indispensável, ou se seria possível lançar mão de alternativas tão ou mais eficazes de formação docente. Recorde-se: a presente pesquisa é apenas um pequeno passo na direção de investigar sobre a formação docente na pós-graduação em direito em sentido estrito. Na senda dela, podem ser desenvolvidas diversas pesquisas de campo apontando de que forma o ensino é e de que forma pode ser abordado e tratado a fim de que os mestres conheçam suas diferentes perspectivas e as levem para sua docência nos cursos de graduação. É o início de um trabalho que se propõe a mapear o intervalo entre o mestre e o professor - para que então possa ser construída a ponte. 


\section{REFERÊNCIAS}

ALMEIDA, Elizangela Santos de. A formação stricto sensu dos professores dos cursos de direito e seus reflexos no ensino jurídico. 2014. Dissertação de Mestrado em Educação. Universidade de Uberaba. Uberaba, MG, 2014.

BRASIL. Coordenação de Aperfeiçoamento de Pessoal de Nível Superior. Plataforma Sucupira. Disponível em:<https://sucupira.capes.gov.br/>. Acesso em: 13 dez. 2015A.

BRASIL. Coordenação de Aperfeiçoamento de Pessoal de Nível Superior. Plataforma Sucupira. Apresentação de Propostas de Cursos Novos - Manual do Usuário. Disponível em:<https://sucupira.capes.gov.br/sucupira/public/lancamento/manual.jsf >. Acesso em: 13 dez. 2015B.

BRASIL. Coordenação de Aperfeiçoamento de Pessoal de Nível Superior. Relatório de Avaliação 2010-2012 Trienal 2013 - Área de avaliação: Direito. Disponível em: <http://www.capes.gov.br/component/content/article/44-avaliacao/4663-direito>. Acesso em:13 dez. 2015C.

DANTAS, Francisco Clementino de San Tiago. A educação jurídica e a crise brasileira. In: RIO, Fgv Direito. Cadernos FGV Direito Rio. Rio de Janeiro: Escola de Direito do Rio de Janeiro da Fundação Getulio Vargas, 2010. Cap. 1. p. 9-38. (Educação e direito). Disponível em: <http://library.jfpb.jus.br/arquivos/ebooks/direito/Cadernos FGV Direito Rio vol.3.pdf>. Acesso em: 13 dez. 2015.

FREIRE, Paulo. Pedagogia da autonomia: saberes necessários à prática educativa. Paz e Terra: 25a ed. São Paulo: Paz e Terra, 2002.

GHIRARDI, José Garcez. Observatório do Ensino do Direito: relatório outubro 2013 Quem é o professor de Direito no Brasil? São Paulo: GV Direito - Núcleo de Metodologia de Ensino, 2013. Disponível em:

<http://direitogv.fgv.br/sites/direitogv.fgv.br/files/arquivos/anexos/oed_-_relatorio_01__quem_e_o_professor_de_direito_no_brasil.pdf>. Acesso em: 13 dez. 2015.

ENSINO e pesquisa nos PPGDs do Brasil. Disponível em:

<https://docs.google.com/forms/d/1Lg4Dk7p6z46wJpncfA2ZEWGoL9pet1U5ONrcjZDCo dg/viewform>. Acesso em: 13 dez. 2015A.

ENSINO e pesquisa nos PPGDs do Brasil (respostas). Disponível em: <https://drive.google.com/open?id=1XWxiu2XU4rBhk6y04GpoCwn9dKOOHyzcipzPKjzRgU>. Acesso em: 13 dez. 2015B.

ENSINO e pesquisa nos PPGDs do Brasil. Resumo das respostas. Disponível em: <https://docs.google.com/forms/d/1Lg4Dk7p6z46wJpncfA2ZEWGoL9pet1U5ONrcjZDCo dg/viewanalytics>. Acesso em: 13 dez. 2015C.

MIZUKAMI, Maria da Graça Nicoletti. Ensino: as abordagens do processo. São Paulo: E.P.U., 1986 
PAGANI, Juliana Ferrari de Oliveira. "A formação dos professores dos cursos de direito no Brasil: A pós-graduação "stricto senso"”. In: Anais do Simpósio da Associação Nacional de Política e Administração da Educação (ANPAE). 2011. Disponível em:

<http://www.anpae.org.br/simposio2011/cdrom2011/PDFs/trabalhosCompletos/comunicac oe sRelatos/0264.pdf>. Acesso em 10 abr. 2016.

RODRIGUES, Horácio Wanderlei. O exercício do magistério superior e o direito educacional brasileiro. Sequência, Florianópolis, UFSC, v. 30, n. 58, jul. 2009, p. 35-46. Disponível em:

<http://periodicos.ufsc.br/index.php/sequencia/article/view/14874/1360>. Acesso em: 13 dez.2015.

VATAN DOS SANTOS, Roberto. Abordagens do processo de ensino-aprendizagem. Integração, a. XI, n. 40, p. 19-31, jan./maio 2005. Disponível em:

<ftp://www.usjt.br/pub/revint/19_40.pdf >. Acesso em: 13 dez. 2015. 


\section{APÊNDICE A}

Nomenclatura das disciplinas voltadas a ensino e a pesquisa encontradas nos currículos e consideradas para as finalidades deste trabalho, conforme extraído da Plataforma Sucupira:

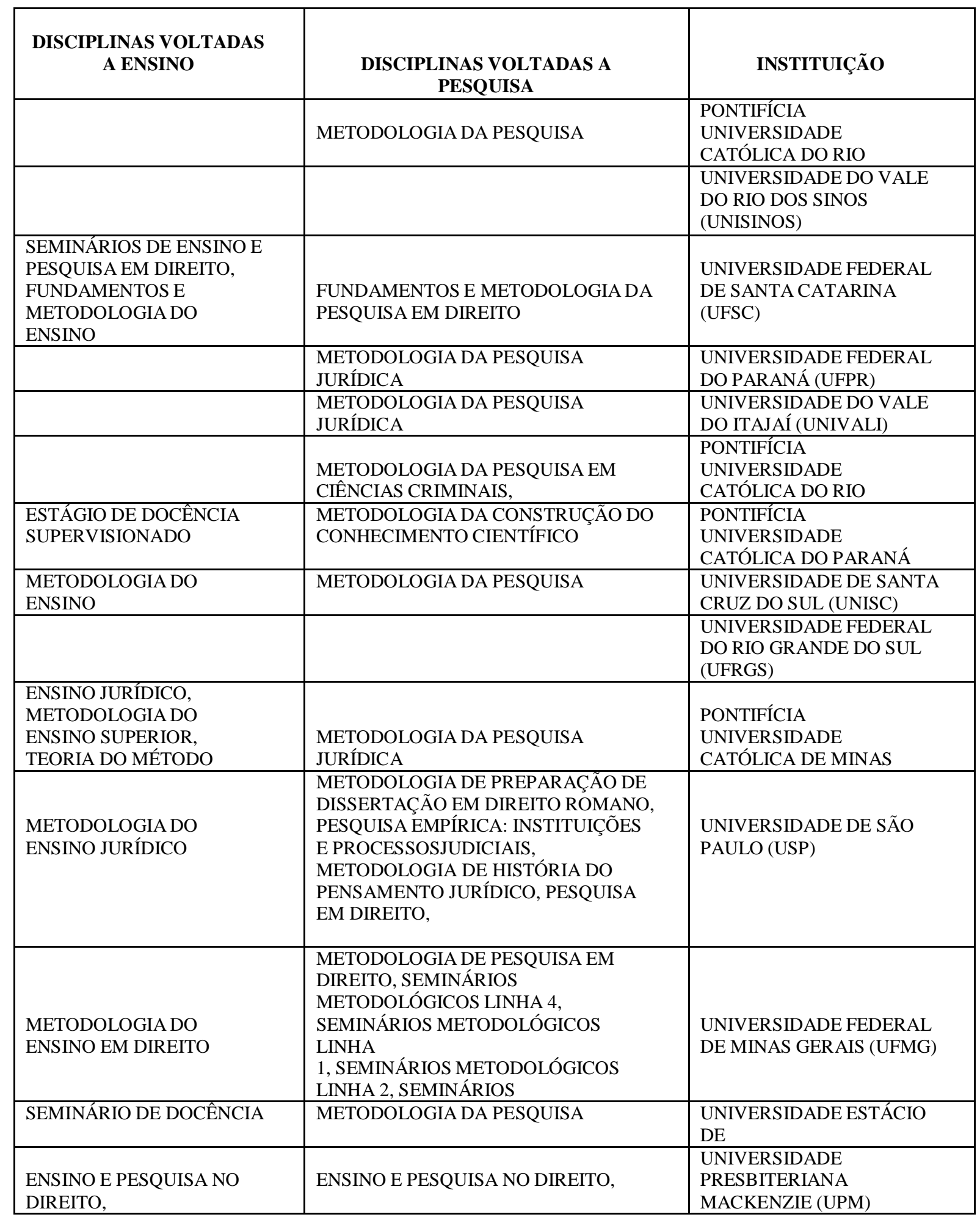




\begin{tabular}{|l|l|l|}
\hline & METODOLOGIA DA PESQUISA EM & \\
& CIÊNCIAS SOCIAIS, SEMINÁRIOS DE & \\
& PESQUISA I, SEMINÁRIOS DE & $\begin{array}{l}\text { UNIVERSIDADE FEDERAL } \\
\text { DA PARAIIBA/JOÃO } \\
\text { ESTÁGIO DOCÊNCIA }\end{array}$ \\
& $\begin{array}{l}\text { PESQUISA } \\
\text { PI, SEMINÁRIOS DE PESQUISA III, } \\
\text { SEMINÁRIOS DE ELABORAÇÃO DE }\end{array}$ & \\
& DISSERTAÇÃO II, SEMINÁRIOS DE & \\
\hline $\begin{array}{l}\text { DIDÁTICA DO ENSINO } \\
\text { JURÍDICO, DIDÁTICA DO }\end{array}$ & METODOLOGIA DA PESQUISA EM & UNIVERSIDADE DE \\
ENSINO SUPERIOR & DIREITO & FORTALEZA (UNIFOR) \\
\hline
\end{tabular}

\begin{tabular}{|c|c|c|}
\hline $\begin{array}{l}\text { PRÁTICA DO ENSINO E DA } \\
\text { FORMAÇÃO EM DIREITO }\end{array}$ & $\begin{array}{l}\text { FORMAÇÃO ACADÊMICA NO } \\
\text { DIREITO, } \\
\text { INVESTIGAÇÃO CIENTÍFICA: DIREITO } \\
\text { E INTERDISCIPLINARIDADE, }\end{array}$ & $\begin{array}{l}\text { UNIVERSIDADE DE } \\
\text { BRASÍLIA (UNB) }\end{array}$ \\
\hline & $\begin{array}{l}\text { FUNDAMENTOS DA METODOLOGIA } \\
\text { CIENTIFICA EM DIREITO }\end{array}$ & $\begin{array}{l}\text { CENTRO UNIVERSITÁRIO } \\
\text { DE }\end{array}$ \\
\hline \multirow[t]{2}{*}{$\begin{array}{l}\text { METODOLOGIA DA } \\
\text { PESQUISA E DO ENSINO, } \\
\text { METODOLOGIA DO } \\
\text { ENSINO JURÍDICO, } \\
\text { METODOLOGIA } \\
\text { DA PESQUISA, DO ENSINO }\end{array}$} & $\begin{array}{l}\text { METODOLOGIA DA PESQUISA E DO } \\
\text { ENSINO, METODOLOGIAS DE } \\
\text { PESQUISA EMPÍRICA EM DIREITO DA } \\
\text { PERSONALIDADE }\end{array}$ & $\begin{array}{l}\text { CENTRO UNIVERSITÁRIO } \\
\text { DE MARINGÁ } \\
\text { (UNICESUMAR) }\end{array}$ \\
\hline & $\begin{array}{l}\text { FUNDAMENTOS DO CONHECIMENTO } \\
\text { APLICADO À METODOLOGIA DA } \\
\text { PESQUISA EM CIÊNCIAS SOCIAIS }\end{array}$ & $\begin{array}{l}\text { CENTRO UNIVERSITÁRIO } \\
\text { DE JOÃO PESSOA (UNIPÊ) }\end{array}$ \\
\hline \multirow[t]{2}{*}{$\begin{array}{l}\text { EDUCAÇÃO, } \\
\text { METODOLOGIA }\end{array}$} & $\begin{array}{l}\text { EDUCAÇÃO, METODOLOGIA E } \\
\text { PESQUISA EM DIREITO }\end{array}$ & $\begin{array}{l}\text { CENTRO UNIVERSITÁRIO } \\
\text { FIEO (UNIFIEO) }\end{array}$ \\
\hline & $\begin{array}{l}\text { TÓPICOS AVANÇADOS DE PESQUISA } \\
\text { EM HISTÓRIA DO PENSAMENTO } \\
\text { JURÍDICO }\end{array}$ & $\begin{array}{l}\text { FACULDADE DAMAS DA } \\
\text { INSTRUÇ } \tilde{O} O \text { CRIST } \tilde{A} \\
\text { (EADIC) }\end{array}$ \\
\hline $\begin{array}{l}\text { FUNDAMENTOS E } \\
\text { METODOLOGIA DO } \\
\text { ENSINO E PESQUISA DO }\end{array}$ & $\begin{array}{l}\text { FUNDAMENTOS E METODOLOGIA DO } \\
\text { ENSINO E PESQUISA DO DIREITO }\end{array}$ & $\begin{array}{l}\text { FACULDADE MERIDIONAL } \\
\text { (IMED) }\end{array}$ \\
\hline \multirow[t]{2}{*}{$\begin{array}{l}\text { DIDÁTICA DO ENSINO DO } \\
\text { DIREITO }\end{array}$} & $\begin{array}{l}\text { METODOLOGIA DE INVESTIGAÇÃO } \\
\text { DA CIÊNCIA DO DIREITO }\end{array}$ & $\begin{array}{l}\text { FUNDAÇÃO DE ENSINO } \\
\text { "EURÍPIDES SOARES DA } \\
\text { ROCHA" (FEESR) } \\
\end{array}$ \\
\hline & $\begin{array}{l}\text { MÉTODOS E TÉCNICAS DE PESQUISA } \\
\text { EM DIREITO }\end{array}$ & $\begin{array}{l}\text { FUNDAÇÃO } \\
\text { UNIVERSIDADE } \\
\text { FEDERAL DE MATO } \\
\text { GROSSO DO SUL (UFMS) }\end{array}$ \\
\hline $\begin{array}{l}\text { METODOLOGIA DO } \\
\text { ENSINO E PESQUISA EM } \\
\text { DIREITO }\end{array}$ & $\begin{array}{l}\text { METODOLOGIA DO ENSINO E } \\
\text { PESQUISA EM DIREITO ( } 2)\end{array}$ & $\begin{array}{l}\text { FUNDAÇÃO } \\
\text { UNIVERSIDADE } \\
\text { FEDERAL DE SERGIPE } \\
\text { (FUFSE) }\end{array}$ \\
\hline \multirow[t]{4}{*}{$\begin{array}{l}\text { METODOLOGIA DO } \\
\text { ENSINO E DA PESQUISA } \\
\text { JURÍDICA }\end{array}$} & $\begin{array}{l}\text { METODOLOGIA DO ENSINO E DA } \\
\text { PESQUISA JURÍDICA, ORIENTAÇÃOD } \\
\text { E DISSERTAÇÃOO I, ORIENTAÇÃOD E } \\
\text { DISSERTAÇA̧O II, ORIENTAÇÃOD E } \\
\text { DISSERTAÇÃO III }\end{array}$ & $\begin{array}{l}\text { UNIVERSIDADE } \\
\text { CATÓLICA DE } \\
\text { PETRÓPOLIS (UCP/RJ) }\end{array}$ \\
\hline & $\begin{array}{l}\text { TEORIA E METODOLOGIA DA } \\
\text { PESQUISA EM DIREITO }\end{array}$ & $\begin{array}{l}\text { UNIVERSIDADE } \\
\text { COMUNITÁRIA DA } \\
\text { REGIÃO DE CHAPECÓ } \\
\text { (UNOCHAPECÓ) } \\
\end{array}$ \\
\hline & $\begin{array}{l}\text { METODOLOGIA DA PESQUISA } \\
\text { JURÍDICA }\end{array}$ & $\begin{array}{l}\text { UNIVERSIDADE CÂNDIDO } \\
\text { MENDES (UCAM) }\end{array}$ \\
\hline & $\begin{array}{l}\text { METODOLOGIA DA PESQUISA } \\
\text { JURÍDICA }\end{array}$ & $\begin{array}{l}\text { UNIVERSIDADE FEDERAL } \\
\text { DE } \\
\text { ALAGOAS (UFAL) }\end{array}$ \\
\hline
\end{tabular}




\begin{tabular}{|c|c|c|}
\hline & $\begin{array}{l}\text { METODOLOGIA DA PESQUISA } \\
\text { JURÍDICA }\end{array}$ & $\begin{array}{l}\text { UNIVERSIDADE FEDERAL } \\
\text { DO ESTADO DO RIO DE } \\
\text { JANEIRO (UNIRIO) } \\
\end{array}$ \\
\hline & $\begin{array}{l}\text { METODOLOGIA DA INVESTIGAÇÃO } \\
\text { CIENTÍFICA ( } 2 \text { ) }\end{array}$ & $\begin{array}{l}\text { UNIVERSIDADE FEDERAL } \\
\text { DO RIO GRANDE DO } \\
\text { NORTE (UFRN) }\end{array}$ \\
\hline \multirow[t]{4}{*}{$\begin{array}{l}\text { PRÁTICA PEDAGÓGICA E } \\
\text { METODOLOGIA DA } \\
\text { EDUCAÇÃO JURÍDICA } \\
\end{array}$} & $\begin{array}{l}\text { ECOLOGIA DOS SABERES APLICADA } \\
\text { Â PESQUISA DO DIREITO }\end{array}$ & $\begin{array}{l}\text { UNIVERSIDADE NOVE DE } \\
\text { JULHO (UNINOVE) }\end{array}$ \\
\hline & $\begin{array}{l}\text { ORIENTAÇÃO DE DISSERTAÇÃO, } \\
\text { ELABORAÇÃO E DEFESA FINAL DE } \\
\text { DISSERTAÇÃO, ELABORAÇÃO E } \\
\text { DEFESA DE PROJETO DE } \\
\text { DISSERTAÇÃO, SEMINÁRIO DE } \\
\text { PESQUISA }\end{array}$ & $\begin{array}{l}\text { UNIVERSIDADE DO OESTE } \\
\text { DE SANTA CATARINA } \\
\text { (UNOESC) }\end{array}$ \\
\hline & $\begin{array}{l}\text { METODOLOGIA DA PESQUISA E DO } \\
\text { TRABALHO CIENTÍFICO }\end{array}$ & $\begin{array}{l}\text { UNIVERSIDADE FEDERAL } \\
\text { DE MATO GROSSO (UFMT) }\end{array}$ \\
\hline & $\begin{array}{l}\text { METODOLOGIA DO TRABALHO } \\
\text { CIENTÍFICO }\end{array}$ & $\begin{array}{l}\text { UNIVERSIDADE FEDERAL } \\
\text { DE GOIÁS (UFG) }\end{array}$ \\
\hline $\begin{array}{l}\text { METODOLOGIA DA } \\
\text { EDUCAÇÃO JURÍDICA, }\end{array}$ & PESQUISA JURÍDICA & $\begin{array}{l}\text { UNIVERSIDADE DO } \\
\text { ESTADO DO AMAZONAS } \\
\text { (UEA) }\end{array}$ \\
\hline $\begin{array}{l}\text { DOCÊNCIA DO ENSINO } \\
\text { SUPERIOR }\end{array}$ & & \\
\hline \multirow[t]{2}{*}{$\begin{array}{l}\text { METODOLOGIA DA } \\
\text { PESQUISA EM DIREITO E } \\
\text { DIDÁTICA DO ENSINO } \\
\text { SUPE }\end{array}$} & $\begin{array}{l}\text { METODOLOGIA DA PESQUISA EM } \\
\text { DIREITO E DIDÁTICA DO ENSINO } \\
\text { SUPE }\end{array}$ & $\begin{array}{l}\text { CENTRO UNIVERSITÁRIO } \\
\text { DAS FACULDADES } \\
\text { METROPOLITANAS } \\
\text { UNIDAS (FMU) }\end{array}$ \\
\hline & $\begin{array}{l}\text { METODOLOGIA DAS CIÊNCIAS } \\
\text { SOCIAIS }\end{array}$ & $\begin{array}{l}\text { UNIVERSIDADE FEDERAL } \\
\text { DO MARANHÃ O (UFMA) }\end{array}$ \\
\hline \multirow[t]{3}{*}{$\begin{array}{l}\text { METODOLOGIA DA AÇÃO } \\
\text { DOCENTE, COMPREENSÃO } \\
\text { CRÍTICA DO PROCESSO DE } \\
\text { CONHECIMENTO, PRÁTICA } \\
\text { DOCENTE }\end{array}$} & $\begin{array}{l}\text { METODOLOGIA DA PESQUISA } \\
\text { CIENTÍFICA }\end{array}$ & $\begin{array}{l}\text { UNIVERSIDADE } \\
\text { PARANAENSE (UNIPAR) }\end{array}$ \\
\hline & $\begin{array}{l}\text { METODOLOGIA DA PESQUISA EM } \\
\text { DIREITO, ORIENTAÇÃO DE } \\
\text { DISSERTAÇÃO }\end{array}$ & $\begin{array}{l}\text { CENTRO UNIVERSITÁRIO } \\
\text { LA SALLE (UNILASALLE) }\end{array}$ \\
\hline & $\begin{array}{l}\text { METODOLOGIA E PESQUISA EM } \\
\text { DIREITO }\end{array}$ & $\begin{array}{l}\text { CENTRO UNIVERSITÁRIO } \\
\text { RITTER DOS REIS } \\
\text { (UNIRITTER) }\end{array}$ \\
\hline $\begin{array}{l}\text { MÉTODOS DE PESQUISA E } \\
\text { ENSINO NO DIREITO }\end{array}$ & $\begin{array}{l}\text { MÉTODOS DE PESQUISA E ENSINO } \\
\text { NO DIREITO }\end{array}$ & $\begin{array}{l}\text { CENTRO UNIVERSITÁRIO } \\
\text { SALESIANO DE SÃO } \\
\text { PAULO (UNISAL) }\end{array}$ \\
\hline \multirow[t]{2}{*}{$\begin{array}{l}\text { PROGRAMA DE } \\
\text { FORMAÇÃO } \\
\text { EM EDUCAÇÃO JURÍDICA }\end{array}$} & PESQUISA EM DIREITO & $\begin{array}{l}\text { ESCOLA DE DIREITO DE } \\
\text { S ̃̃O } \\
\text { PAULO (FGV DIREITO SP) }\end{array}$ \\
\hline & & $\begin{array}{l}\text { FACULDADE DE DIREITO } \\
\text { DO }\end{array}$ \\
\hline $\begin{array}{l}\text { METODOLOGIA DE } \\
\text { PESQUISA E DO ENSINO } \\
\text { EM DIREITS }\end{array}$ & $\begin{array}{l}\text { METODOLOGIA DE PESQUISA E DO } \\
\text { ENSINO EM DIREITO }\end{array}$ & $\begin{array}{l}\text { FACULDADE ESCOLA } \\
\text { PAULISTA DE DIREITO } \\
\text { (FACEPD) }\end{array}$ \\
\hline
\end{tabular}




\begin{tabular}{|c|c|c|}
\hline $\begin{array}{l}\text { ESTÁGIO DE DOCÊNCIA I, } \\
\text { ESTÁGIO DE DOCÊNCIA II }\end{array}$ & $\begin{array}{l}\text { SEMINÁRIOS DE PESQUISA: } \\
\text { JURISDIÇÃO CONSTITUCIONAL E } \\
\text { DEMOCRACIA, ORIENTAÇÃO DE } \\
\text { DISSERTAÇÃO I, ORIENTAÇÃO DE } \\
\text { DISSERTAÇÃO II, ORIENTAÇÃO DE } \\
\text { DISSERTAÇÃO III, ORIENTAÇÃO DE } \\
\text { DISSERTAÇÃO IV, SEMINÁRIOS DE } \\
\text { PESQUISA: RELAÇÕES SOCIAIS E } \\
\text { DIMENSÕES DO PODER }\end{array}$ & $\begin{array}{l}\text { FUNDAÇÃO } \\
\text { UNIVERSIDADE DE PASSO } \\
\text { FUNDO (FUPF) }\end{array}$ \\
\hline $\begin{array}{l}\text { EDUCAÇÃO JURÍDICA: } \\
\text { CONTORNOS } \\
\text { EPISTEMOLÓGICOS E } \\
\text { POLÍTICO-INSTITUCIONAIS }\end{array}$ & $\begin{array}{l}\text { PESQUISA EMPÍRICA EM DIREITO, } \\
\text { DIREITO, CIÊNCIA E MÉTODO, }\end{array}$ & $\begin{array}{l}\text { UNIVERSIDADE DE SÃO } \\
\text { PAULO/ RIBEIRÃO PRETO } \\
\text { (USP/RP) }\end{array}$ \\
\hline \multirow[t]{4}{*}{ DOCÊNCIA ORIENTADA } & $\begin{array}{l}\text { METODOLOGIA E PESQUISA EM } \\
\text { DIREITO }\end{array}$ & $\begin{array}{l}\text { UNIVERSIDADE FEDERAL } \\
\text { DE SANTA MARIA (UFSM) }\end{array}$ \\
\hline & $\begin{array}{l}\text { SEMINÁRIOS DE TÉCNICA DE } \\
\text { PESQUISA } \\
\text { I, SEMINÁRIOS DE TÉCNICA DE } \\
\text { PESQUISA II, SEMINÁRIOS DE } \\
\text { PESQUISA JURÍDICA }\end{array}$ & $\begin{array}{l}\text { UNIVERSIDADE FEDERAL } \\
\text { DE UBERLÂNDIA (UFU) }\end{array}$ \\
\hline & $\begin{array}{l}\text { FUNDAMENTOS DE METODOLOGIA } \\
\text { DA PESQUISA JURÍDICA, } \\
\text { ELABORAÇÃO DE DISSERTAÇÃO DE } \\
\text { MESTRADO }\end{array}$ & $\begin{array}{l}\text { ESCOLA SUPERIOR DOM } \\
\text { HELDER CÂMARA } \\
\text { (ESDHC) }\end{array}$ \\
\hline & $\begin{array}{l}\text { EPISTEMOLOGIA E METODOLOGIA } \\
\text { JURÍDICA }\end{array}$ & $\begin{array}{l}\text { INSTITUTO BRASILIENSE } \\
\text { DE DIREITO PÚBLICO (IDP) }\end{array}$ \\
\hline \multirow{2}{*}{$\begin{array}{l}\text { METODOLOGIA DO } \\
\text { ENSINO E } \\
\text { DA PESQUISA }\end{array}$} & $\begin{array}{l}\text { METODOLOGIA DO ENSINO E DA } \\
\text { PESQUISA }\end{array}$ & $\begin{array}{l}\text { UNIVERSIDADE FEDERAL } \\
\text { FLUMINENSE (UFF) }\end{array}$ \\
\hline & $\begin{array}{l}\text { SEMINÁRIOS DE PESQUISA, } \\
\text { METODOLOGIA DA PESQUISA EM } \\
\text { DIREITO }\end{array}$ & $\begin{array}{l}\text { FUNDAÇÃO GETÚLIO } \\
\text { VARGAS/RJ (FGV/RJ) }\end{array}$ \\
\hline $\begin{array}{l}\text { ESTÁGIO DE DOCÊNCIA I, } \\
\text { ESTÁGIO DE DOCÊNCIA II, } \\
\text { ESTÁGIO DE DOCÊNCIA III, } \\
\text { ESTÁGIO DE DOCÊNCIA IV }\end{array}$ & $\begin{array}{l}\text { TAREFA ESPECIAL DE REDAÇÃO DE } \\
\text { DISSERTAÇÃO, METODOLOGIA DA } \\
\text { PESQUISA EM DIREITO, } \\
\text { METODOLOGIA DA PESQUISA E DO } \\
\text { ENSINO EM DIREITO }\end{array}$ & $\begin{array}{l}\text { UNIVERSIDADE FEDERAL } \\
\text { DE JUIZ DE FORA (UFJF) }\end{array}$ \\
\hline ESTÁGIO DE DOCÊNCIA & $\begin{array}{l}\text { SEMINÁRIO DE PESQUISA I, } \\
\text { SEMINÁRIO } \\
\text { DE PESQUISA II, SEMINÁRIO DE } \\
\text { PESQUISA III, METODOLOGIA DA } \\
\text { PESQUISA JURÍDICA, } \\
\end{array}$ & $\begin{array}{l}\text { UNIVERSIDADE FEDERAL } \\
\text { DO RIO GRANDE (FURG) }\end{array}$ \\
\hline
\end{tabular}




\begin{tabular}{|c|c|c|}
\hline & $\begin{array}{l}\text { METODOLOGIA DA PESQUISA } \\
\text { JURÍDICA }\end{array}$ & $\begin{array}{l}\text { CENTRO UNIVERSITÁRIO } \\
\text { DO ESTADO DO PARÁ } \\
\text { (CESUPA) }\end{array}$ \\
\hline & METODOLOGIA DA PESQUISA & $\begin{array}{l}\text { UNIVERSIDADE DE } \\
\text { RIBEIRÃO PRETO }\end{array}$ \\
\hline \multirow[t]{2}{*}{$\begin{array}{l}\text { METODOLOGIA DO } \\
\text { ENSINO } \\
\text { JURÍDICO E ESTÁGIO } \\
\end{array}$} & $\begin{array}{l}\text { METODOLOGIA DA PESQUISA } \\
\text { JURÍDICA }\end{array}$ & $\begin{array}{l}\text { UNIVERSIDADE DE } \\
\text { ITAÚNA (UI) }\end{array}$ \\
\hline & METODOLOGIA DA PESQUISA & $\begin{array}{l}\text { UNIVERSIDADE DA } \\
\text { AMAZÔNIA (UNAMA) }\end{array}$ \\
\hline \multirow[t]{2}{*}{$\begin{array}{l}\text { METODOLOGIA DO } \\
\text { ENSINO SUPERIOR, } \\
\text { ESTÁGIO DE DOCÊNCIA }\end{array}$} & $\begin{array}{l}\text { SEMINÁRIO DE DISSERTAÇÃO, } \\
\text { PROJETO DE DISSERTAÇÃO, } \\
\text { DISSERTAÇÃO }\end{array}$ & $\begin{array}{l}\text { UNIV. REGIONAL DO } \\
\text { NOROESTE DO ESTADO } \\
\text { DO RIO GRANDE DO SUL } \\
\text { (UNIJUÍ) }\end{array}$ \\
\hline & $\begin{array}{l}\text { MÉTODOS E TÉCNICAS DA PESQUISA } \\
\text { EM DIREITO }\end{array}$ & $\begin{array}{l}\text { UNIVERSIDADE } \\
\text { TIRADENTES (UNIT-SE) }\end{array}$ \\
\hline \multirow[t]{2}{*}{$\begin{array}{l}\text { METODOLOGIA DO } \\
\text { ENSINO } \\
\text { JURÍDICO, ESTÁGIO DE } \\
\text { DOCÊNCIA I, ESTÁGIO DE } \\
\text { DOCÊNCIA II, ESTÁGIO DE } \\
\text { DOCÊNCIA III, ESTÁGIO DE }\end{array}$} & $\begin{array}{l}\text { METODOLOGIA DA PESQUISA } \\
\text { JURÍDICA }\end{array}$ & $\begin{array}{l}\text { UNIVERSIDADE FUMEC } \\
\text { (FUMEC) }\end{array}$ \\
\hline & $\begin{array}{l}\text { METODOLOGIA DA PESQUISA } \\
\text { JURÍDICA }\end{array}$ & $\begin{array}{l}\text { UNIVERSIDADE } \\
\text { ESTADUAL } \\
\text { DO NORTE DO PARANÁ } \\
\end{array}$ \\
\hline \multirow[t]{2}{*}{ ESTÁGIO DOCENTE } & $\begin{array}{l}\text { EPISTEMOLOGIA E METODOLOGIA } \\
\text { DO }\end{array}$ & $\begin{array}{l}\text { CENTRO UNIVERSITÁRIO } \\
\text { CURITIBA (UNICURITIBA) }\end{array}$ \\
\hline & & $\begin{array}{l}\text { CENTRO UNIVERSITÁRIO } \\
\text { AUTÔNOMO DO BRASIL } \\
\text { (UNIBRASIL) }\end{array}$ \\
\hline $\begin{array}{l}\text { METODOLOGIA DO } \\
\text { ENSINO }\end{array}$ & $\begin{array}{l}\text { METODOLOGIA DA PESQUISA EM } \\
\text { DIREITO (2) }\end{array}$ & $\begin{array}{l}\text { FACULDADE DE DIREITO } \\
\text { DE }\end{array}$ \\
\hline $\begin{array}{l}\text { EDUCAÇÃO, } \\
\text { METODOLOGIA } \\
\text { E DIDATICA DO ENSINO } \\
\text { SUPERIOR EM DIREITO, } \\
\text { METODOLOGIA } \\
\text { CIENTÍFICA E DIDÁTICA }\end{array}$ & $\begin{array}{l}\text { METODOLOGIA CIENTÍFICA E } \\
\text { DIDÁTICA DO ENSINO SUPERIOR }\end{array}$ & $\begin{array}{l}\text { PONTIFÍCIA } \\
\text { UNIVERSIDADE } \\
\text { CATÓLICA DE SÃO PAULO } \\
\text { (PUC/SP) }\end{array}$ \\
\hline ESTÁGIO DOCÊNCIA (2) & $\begin{array}{l}\text { SEMINÁRIO DE METODOLOGIA E } \\
\text { DISSERTAÇÃO, DISSERTAÇÃO DE } \\
\text { MESTRADO }\end{array}$ & $\begin{array}{l}\text { PONTIFÍCIA } \\
\text { UNIVERSIDADE } \\
\text { CATÓLICA DO RIO DE } \\
\end{array}$ \\
\hline \multirow[t]{4}{*}{$\begin{array}{l}\text { MÉTODOS DA PESQUISA E } \\
\text { DO ENSINO SUPERIOR }\end{array}$} & $\begin{array}{l}\text { MÉTODOS DA PESQUISA E DO } \\
\text { ENSINO SUPERIOR }\end{array}$ & $\begin{array}{l}\text { UNIV. REGIONAL } \\
\text { INTEGRADA DO ALTO } \\
\text { URUGUAIE DAS MISSÕES } \\
\text { (URI) }\end{array}$ \\
\hline & $\begin{array}{l}\text { METODOLOGIA APLICADA À } \\
\text { PESQUISA }\end{array}$ & $\begin{array}{l}\text { UNIVERSIDADE } \\
\text { CATÓLICA }\end{array}$ \\
\hline & $\begin{array}{l}\text { METODOLOGIA DA PESQUISA (5), } \\
\text { SEMINÁRIOS DE PESQUISA (5), }\end{array}$ & $\begin{array}{l}\text { UNIVERSIDADE } \\
\text { CATÓLICA }\end{array}$ \\
\hline & METODOLOGIA DA PESQUISA & $\begin{array}{l}\text { UNIVERSIDADE DE } \\
\text { CAXIAS }\end{array}$ \\
\hline $\begin{array}{l}\text { PEDAGOGIA JURÍDICA E } \\
\text { ESTÁGIO DOCÊNCIA }\end{array}$ & $\begin{array}{l}\text { METODOLOGIA DA PESQUISA } \\
\text { JURÍDICA, ORIENTAÇÃO DE } \\
\text { DISSERTAÇÃO I, ORIENTAÇÃO DE } \\
\text { DISSERTAÇÃO II }\end{array}$ & $\begin{array}{l}\text { UNIVERSIDADE DE } \\
\text { MARÍLIA (UNIMAR) }\end{array}$ \\
\hline \multirow[t]{2}{*}{ ESTÁGIO DOCENTE I } & $\begin{array}{l}\text { SEMINÁRIO DE PESQUISA E } \\
\text { ORIENTAÇÃO I }\end{array}$ & $\begin{array}{l}\text { UNIVERSIDADE DO } \\
\text { ESTADO }\end{array}$ \\
\hline & $\begin{array}{l}\text { FUNDAMENTOS METODOLÓGICOS } \\
\text { DE PESQUISA JURÍDICA }\end{array}$ & $\begin{array}{l}\text { UNIVERSIDADE } \\
\text { EST.PAULISTA JÚLIO DE } \\
\text { MESQUITA FILHO/FRANCA } \\
\text { (UNESP/FR) }\end{array}$ \\
\hline
\end{tabular}




\begin{tabular}{|c|c|c|}
\hline $\begin{array}{l}\text { TIROCÍNIO DOCENTE } \\
\text { ORIENTADO }\end{array}$ & $\begin{array}{l}\text { METODOLOGIA DA PESQUISA EM } \\
\text { DIREITO, PESQUISA ORIENTADA, } \\
\text { PROJETO DE DISSERTAÇÃO, } \\
\text { SEMINÁRIOS DE PESQUISA } \\
\end{array}$ & $\begin{array}{l}\text { UNIVERSIDADE FEDERAL } \\
\text { DA BAHIA (UFBA) }\end{array}$ \\
\hline & SEMINÁRIO DE DISSERTAÇÃO & $\begin{array}{l}\text { UNIVERSIDADE FEDERAL } \\
\text { DE PERNAMBUCO (UFPE) }\end{array}$ \\
\hline \multirow[t]{3}{*}{$\begin{array}{l}\text { ESTÁGIO DE DOCÊNCIA, } \\
\text { METODOLOGIA DO } \\
\text { ENSINO JURÍDICO } \\
\end{array}$} & $\begin{array}{l}\text { DISSERTAÇÃO, PESQUISA JURÍDICA E } \\
\text { ELABORAÇÃO DE DISSERTAÇÃO }\end{array}$ & $\begin{array}{l}\text { UNIVERSIDADE FEDERAL } \\
\text { DO CEARÁ (UFC) }\end{array}$ \\
\hline & METODOLOGIA CIENTIFICA (2) & $\begin{array}{l}\text { UNIVERSIDADE FEDERAL } \\
\text { DO PARÁ (UFPA) }\end{array}$ \\
\hline & $\begin{array}{l}\text { PESQUISA DE DISSERTAÇÃO DE } \\
\text { MESTRADO, SEMINÁRIO DE } \\
\text { PESQUISA, METODOLOGIA JURIDICA, }\end{array}$ & $\begin{array}{l}\text { UNIVERSIDADE FEDERAL } \\
\text { DO RIO DE JANEIRO (UFRJ) }\end{array}$ \\
\hline \multirow[t]{2}{*}{$\begin{array}{l}\text { FUNDAMENTOS DO } \\
\text { CONHECIMENTO } \\
\text { APLICADOS À PESQUISA E } \\
\text { AO ENSINO DO DIREITO } \\
\end{array}$} & $\begin{array}{l}\text { FUNDAMENTOS DO CONHECIMENTO } \\
\text { APLICADOS À PESQUISA E AO } \\
\text { ENSINO DO DIREITO }\end{array}$ & $\begin{array}{l}\text { UNIVERSIDADE } \\
\text { METODISTA DE } \\
\text { PIRACICABA (UNIMEP) } \\
\end{array}$ \\
\hline & $\begin{array}{l}\text { DISSERTAÇÃO I - QUALIFICAÇÃO, } \\
\text { DISSERTAÇÃO II - DEFESA, PESQUISA } \\
\text { JURÍDICA AVANÇADA }\end{array}$ & $\begin{array}{l}\text { UNIVERSIDADE } \\
\text { CATÓLICA DE BRASÍLIA } \\
(\text { (UR) }\end{array}$ \\
\hline \multirow[t]{3}{*}{$\begin{array}{l}\text { ESTÁGIO DE DOCÊNCIA } \\
\text { NA GRADUAÇÃO I, } \\
\text { ESTÁGIO DE DOCÊNCIA } \\
\text { NA GRADUAÇÃO II, } \\
\text { ESTÁGIO DE DOCÊNCIA } \\
\text { NA GRADUAÇÃO III, } \\
\text { ESTÁGIO DE DOCÊNCIA } \\
\text { NA GRADUAÇÃO IV }\end{array}$} & $\begin{array}{l}\text { DISSERTAÇÃO I, DISSERTAÇÃO II, } \\
\text { DISSERTAÇÃO III, DISSERTAÇÃO IV, } \\
\text { METODOLOGIA DA PESQUISA } \\
\text { JURÍDICO CIENTIIFICA }\end{array}$ & $\begin{array}{l}\text { UNIVERSIDADE } \\
\text { ESTADUAL DE LONDRINA } \\
\text { (UEL) }\end{array}$ \\
\hline & PESQUISA ORIENTADA & $\begin{array}{l}\text { UNIVERSIDADE FEDERAL } \\
\text { DO ESPÍRITO SANTO }\end{array}$ \\
\hline & $\begin{array}{l}\text { METODOLOGIAS, PESQUISAS E } \\
\text { CONSTRUÇÃO DO CONHECIMENTO } \\
\text { (ÁREA DE CONCENTRAÇÃO) } \\
\end{array}$ & $\begin{array}{l}\text { UNIVERSIDADE VEIGA DE } \\
\text { ALMEIDA (UVA) }\end{array}$ \\
\hline $\begin{array}{l}\text { METODOLOGIA DA } \\
\text { PESQUISA E DO ENSINO } \\
\text { JURÍDICO, ESTÁGIO DE } \\
\text { DOCÊNCIA I, ESTÁGIO DE } \\
\text { DOCÊNCIA II }\end{array}$ & $\begin{array}{l}\text { METODOLOGIA DA PESQUISA E DO } \\
\text { ENSINO JURÍDICO, LINGUAGEM E } \\
\text { PESQUISA JURÍDICA }\end{array}$ & $\begin{array}{l}\text { FACULDADE DE DIREITO } \\
\text { MILTON CAMPOS (FDMC) }\end{array}$ \\
\hline \multirow[t]{2}{*}{$\begin{array}{l}\text { METODOLOGIA DE } \\
\text { PESQUISA E DO ENSINO } \\
\text { EM DIREITO }\end{array}$} & $\begin{array}{l}\text { METODOLOGIA DA PESQUISA } \\
\text { CIENTÍFICA, METODOLOGIA DE } \\
\text { PESQUISA E DO ENSINO EM DIREITO }\end{array}$ & $\begin{array}{l}\text { FACULDADE AUTÔNOMA } \\
\text { DE DIREITO (FADISP) }\end{array}$ \\
\hline & & $\begin{array}{l}\text { CENTRO UNIVERSITÁRIO } \\
\text { DE BAURU (ITE) }\end{array}$ \\
\hline
\end{tabular}

